\title{
Apply Deep Learning Image Recognition Technique to Promote Green Consumer Behavior
}

\author{
Wan-Yun $\mathrm{LU}^{1}$ and Ming-Chuan CHIU \\ a National Tsing Hua University, Taiwan
}

\begin{abstract}
As the exhaustion of earth resource and climate change, people are paying more and more attention to the sustainable issues nowadays. Among these issues, the carbon emission is considered to be an important indicator in determining environmental impacts. However, lots of customers have limited understanding of the amount of carbon emission in their daily consumption. Thus, this research aims to utilize the Convolutional Neural Network (CNN) of Deep Learning to provide customers information about carbon emission while they are shopping, and consequently encourage customers' behaviors in green consumption. This study will further integrate the technology with expense tracking software, which can help customers develop the habit of green consumption behavior to achieve better sustainable society.
\end{abstract}

Keywords. Deep Learning, Convolutional Neural Network, Green Consumption Behavior, Carbon Emission, Sustainable Consumption Behavior

\section{Introduction}

Since Industrial Revolution, human society has rapidly developed, but it has also caused a large amount of greenhouse gas emissions such as carbon dioxide, methane and hydrofluorocarbons, which indirectly caused global warming and climate changing. Although the concept of carbon footprint has been proposed for many years, consumers have little understanding about it. Therefore, it is impossible for those consumers to go green. Even the environmentalists who cares for the earth cannot record the carbon footprint of all products on the market.

At present, the Environmental Protection Administration of the Executive Yuan in Taiwan is implementing carbon labeling to provide consumers with purchasing information and supervise manufacturers to reduce carbon. Nonetheless, the assessment of carbon emissions of the entire product takes time and resources, causing it difficult to popularize and only few manufacturers applying for it. Now, the carbon emissions of food have been calculated and published on the Internet by many companies, but most consumers do not actively use it when making purchasing decisions. If the food ingredient is more complex, consumers even need to do some calculations, which is very inconvenient. Hence, if it is possible to integrate the information on the Internet and provide appropriate information when consumers are choosing food, consumers may choose foods that have less carbon footprints.

\footnotetext{
${ }^{1}$ Corresponding Author, Email: xm3j03mp6@gmail.com.
} 
In recent years, the technology of deep learning has developed rapidly and gradually become popular. There are many open resources available, among all of them, TensorFlow $^{\odot}$, which is launched by Google, is the most famous. By using the open source code provided by TensorFlow ${ }^{\odot}$, one can develop artificial intelligence related technologies by himself or herself. Take image recognition technology for example, TensorFlow $^{\odot}$ provides a model trained with Convolutional Neural Network (CNN) to correctly identify what the input image is.

On the other hand, according to the literature, it is helpful to promote green consumption behavior if we can provide the relevant information to consumers. The current methods in the market is mostly to print information on the packages, or scan QR code. Both methods still need to consume printing ink, and sometimes the word is too small and hard to see; moreover, if the information needs to be updated, it is necessary to re-package, which is very inconvenient wasteful. Therefore, this study hopes to develop a new system that can easily and quickly provide users with food information by combining new deep learning technologies with mobile phone to improve current situation.

\section{Literature review}

\subsection{Carbon footprint}

According to Executive Yuan in Taiwan[1], Carbon Footprint can be defined as the direct and indirect greenhouse gas emissions generated by an activity or the entire life cycle of a product. The food carbon footprint explored in this study is the greenhouse gas emissions for individual product life cycles; the so-called "product carbon footprint" .

In recent years, the carbon footprint has been used as a standard for assessing the impact of countries, businesses or products on the global environment. In 2016, the Paris Agreement signed by 195 countries around the world also pointed out that it is necessary to reduce greenhouse gas emissions as soon as possible. However, Tutton[2] shows that several reports from the International Energy Agency pointed out that although carbon emissions have slowed down in recent years, carbon emissions in 2018 have reached new heights, contrary to the Paris agreement. It can be seen that both enterprises and consumers must pay more attention to and practice low-emission life.

The carbon footprint of food takes the factors of planting, feeding, maintenance, transportation methods, and transportation distance into account. Because the calculation method is complex, it is difficult to judge through intuition or memorize mechanically. Usually, consumers can get the relative information about carbon emissions of food through the food carbon footprint calculator or the carbon label posted on the product. Chen[3] pointed out that consumers are highly aware of the carbon labeling practice and believe that carbon labeling can help people to improve energy conservation and carbon reduction. Also, the results of the survey in Chen[3] can be found that women, married, children, and older consumers have a higher awareness of carbon labeling and a higher willingness to accept green product. It can be seen that providing food carbon footprint during consumption can effectively promote green consumption behavior, but because there are fewer carbon label products and consumers do not actively use the food carbon footprint calculator even though many websites are currently available for free, the service rate is not expected to be high. If this situation can be improved and the 
convenience of usability is increased, consumers can have a higher chance to be encouraged to purchase low-carbon food.

\subsection{Green consumption behavior}

Lin and Huang[4] found that up to $73 \%$ of consumers without green consumption habits do not understand green products because they don't know enough about the characteristics and scope of green products, and $22 \%$ of such consumers don't know where they can purchase green products; more environmentally conscious consumers are willing to go green, and such consumers are more concerned with the information, novelty and emotional links provided by the products than the price and quality. Zhu[5] pointed out increased convenience can help consumers realize the idea of green consumption. Joshi and Rahman[6] mentioned that most consumers have the intention to buy green products, but at the time of purchase, the inconvenience and higher price or bad brand impression can become an obstacle between intention and behavior, affecting its green consumption. Motoshita[7] believed information disclosure through visualization can increase consumers' incentives to reduce carbon emissions. Judge[8] used the theory of planned behavior to analyze homebuyers' green purchase intention, and the result showed subjective norms would be a strong predictor, and attitudes, perceived behavioral control and green consumer identity were also significant predictors of purchase intentions.

On the other hand, Lockie[9] described that consumers are lack of information on the environmental impact of food consumption, and the emphasis on environmental impact alone cannot successfully influence consumers to eat more environmentally friendly. Maniatis[10] mentioned that when purchasing green products, consumers will strike a balance between their awareness of environment protection and the economic benefits of the products. Second, the appearance or labels of the product will also be considered as a factor of purchase, but the intention may also be affected by advertisement or wrong news information. It depends on whether the consumers have sufficient knowledge about the environment sustainability issues. Khan and Mohsin[11] used the consumer value model to identify the main factors affecting green consumption behavior. Functional value (price), social value and environmental value have a significant positive impact on the choice of sustainable behavior; instead, the influence of emotional and functional value (quality) are not significant. Impact, risk value and cognitive value will have a negative impact.

According to the research cited above, providing information about carbon emissions of foods in innovative and interesting ways can indeed increase the incentives for consumers to purchase low-carbon foods, especially for women and those who care about the environmental protection. And compared to the traditional labeling methods, new system designed by this research can help consumers have a better understanding of the impact of the food consumption on the earth.

\section{Method}

\subsection{The system framework}

The purpose of this study is to encourage consumers to go green through artificial intelligence technology. The research methods can be divided into three steps. First, 
create a web page to record consumer data and upload photos for every food consumption. The Table Schema is shown in Figure 1. Second, after consumers upload food photos, the deep learning picture recognition technology can identify food category. Third, the website will show the carbon footprint and nutrients of the food provided by CleanMetrics and Health Promotion Administration, Ministry of Health and Welfare in Taiwan.

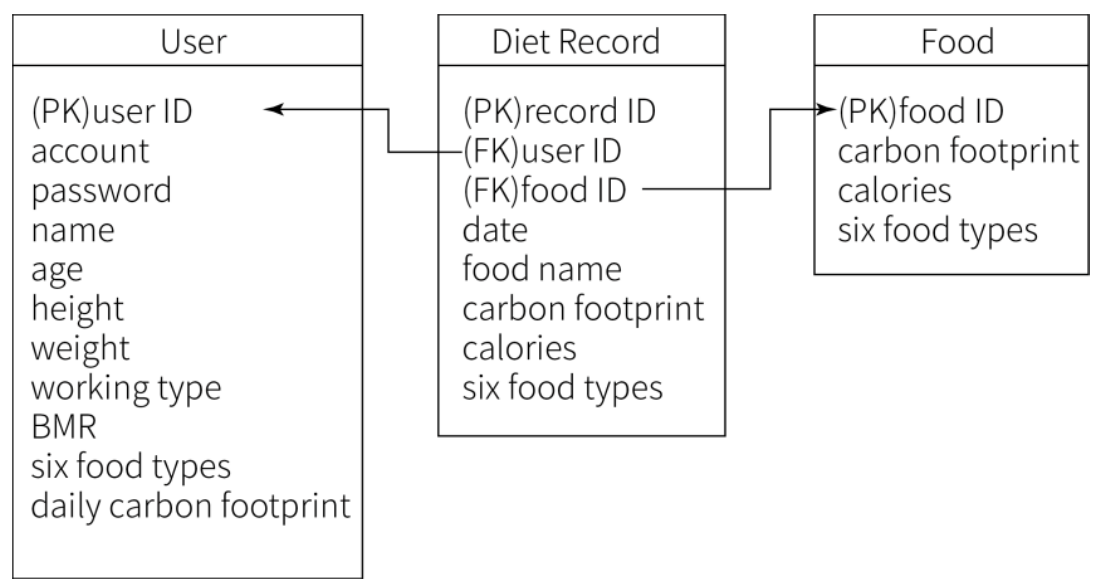

Figure 1. The table schema of website.

\subsection{Convolutional Neural Network (CNN)}

This study used the TensorFlow ${ }^{\odot}$ Inception-v3 to identify images uploaded by consumers. Inception-v3 is a CNN model that Google launched in 2015. According to Google Cloud[12], the model itself is made up of symmetric and asymmetric building blocks, including convolutions, average pooling, max pooling, concats, dropouts, and fully connected layers. For this model, the ImageNet dataset is composed of 1,331,167 images which are split into training and evaluation datasets containing 1,281,167 and 50,000 images, respectively. There are 48 layers in the network with rectified linear units as activation function that can classify images into about 1000 categories and attain $77.2 \%$ validation accuracy. The input size is $299 \times 299 \times 3$, and the output size is $8 \times 8 \times$ 2048. A dropout with rate of 0.2 is applied before the fully connected layers as means of regularization, the filter size is $3 \times 3$, and the architecture of it is shown in Figure 2.

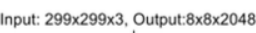

!

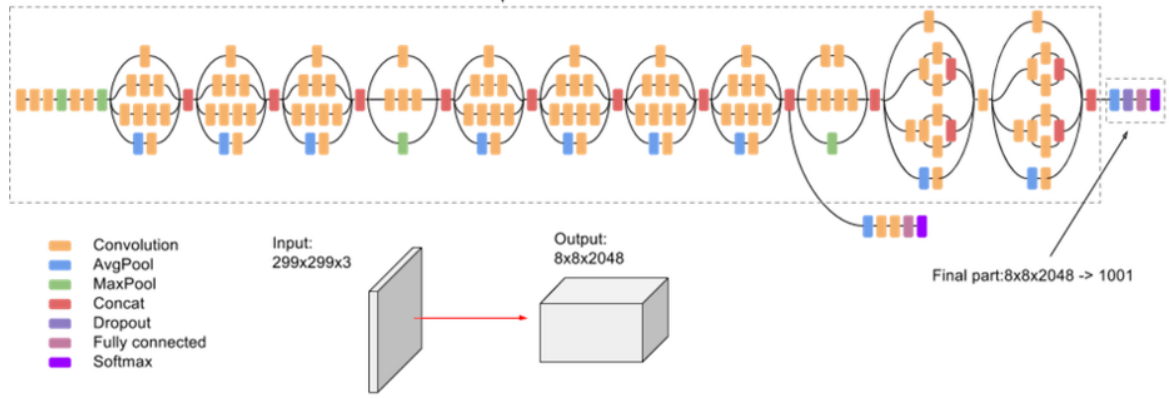

Figure 2. The architecture of Inception-v3.[x]. 


\subsection{Carbon footprint and nutrients of food}

After successfully identifying the food image, system will display the carbon emissions and nutrients of the food, helping consumers to choose foods with similar nutrients but lower carbon emissions at the time of purchase. The carbon emissions shown in this study are referenced from [13]. CleanMetrics is a company that analyzes the circular economy and provides product life cycle assessment services. It has a rich information of carbon footprint, and its website has a food carbon emission calculator that estimates carbon emissions based on food type, food portions and transportation distance. It is difficult to know the origin of food by image recognition alone. Thus, this study will ignore the carbon footprint generated during transportation.

\subsection{Usability test}

The System Usability Scale (SUS) is used as a pre-test tool to evaluate the usability of the website. SUS was invented by John Brooke in 1986 and has been widely applied to test the usefulness of a system, product, or service for many years due to its quick and cheap cost. There are ten-item attitude Likert scale, and users will be asked for answering them after using the website. According to Sauro[14], the SUS score under 68 can be considered as failing. The 10 questions are shown in Table 1.

Table 1. 10 questions of SUS.

\begin{tabular}{|c|c|c|c|c|c|c|}
\hline & & $\begin{array}{l}\text { Strongly } \\
\text { Disagree }\end{array}$ & $\begin{array}{l}\text { Somewhat } \\
\text { Disagree }\end{array}$ & Neutral & $\begin{array}{l}\text { Somewhat } \\
\text { Agree }\end{array}$ & $\begin{array}{c}\text { Strongly } \\
\text { Agree }\end{array}$ \\
\hline 1 & $\begin{array}{l}\text { I think I would like to use this } \\
\text { tool frequently. }\end{array}$ & $\square$ & $\square$ & $\square$ & $\square$ & $\square$ \\
\hline 2 & $\begin{array}{l}\text { I found the tool unnecessarily } \\
\text { complex. }\end{array}$ & $\square$ & $\square$ & $\square$ & $\square$ & $\square$ \\
\hline 3 & $\begin{array}{l}\text { I thought the tool was easy to } \\
\text { use. }\end{array}$ & $\square$ & $\square$ & $\square$ & $\square$ & $\square$ \\
\hline 4 & $\begin{array}{l}\text { I think that I would need the } \\
\text { support of a technical person to } \\
\text { be able to use this system. }\end{array}$ & $\square$ & $\square$ & $\square$ & $\square$ & $\square$ \\
\hline 5 & $\begin{array}{l}\text { I found the various functions in } \\
\text { this tool were well integrated. }\end{array}$ & $\square$ & $\square$ & $\square$ & $\square$ & $\square$ \\
\hline 6 & $\begin{array}{l}\text { I thought there was too much } \\
\text { inconsistency in this tool. }\end{array}$ & $\square$ & $\square$ & $\square$ & $\square$ & $\square$ \\
\hline 7 & $\begin{array}{l}\text { I would imagine that most } \\
\text { people would learn to use this } \\
\text { tool very quickly. }\end{array}$ & $\square$ & $\square$ & $\square$ & $\square$ & $\square$ \\
\hline 8 & $\begin{array}{l}\text { I found the tool very } \\
\text { cumbersome to use. }\end{array}$ & $\square$ & $\square$ & $\square$ & $\square$ & $\square$ \\
\hline 9 & $\begin{array}{l}\text { I felt very confident using the } \\
\text { tool. }\end{array}$ & $\square$ & $\square$ & $\square$ & $\square$ & $\square$ \\
\hline 10 & $\begin{array}{l}\text { I needed to learn a lot of things } \\
\text { before I could get going with } \\
\text { this tool. }\end{array}$ & $\square$ & $\square$ & $\square$ & $\square$ & $\square$ \\
\hline
\end{tabular}




\section{Results and Discussions}

\subsection{Website functions}

In order to improve consumers' willingness to use and system usability, this study added the function of recording calories and food nutrients after establishing the system according to the aforementioned methods, so that consumers can eat healthy and record their daily food carbon footprint. The final website and usage process is shown in Figure 3 .

First, consumers need to fill in gender, age, height, weight and work type when registering their accounts, and the website will calculate the Basal Metabolic Rate (BMR) and the six different types of food needs according to their user data. The BMR formula is referenced from [16], and the classification of six different types of food is based on the information provided by [17].

After successful registration, the consumers can click to upload an image or take a photo with the mobile phone, uploading the photo to the server for image recognition, and then display the estimated carbon footprint, calories and six different types of food portions on the webpage. In addition, the website will also show the total daily food intake, all food carbon footprint records and the average daily carbon footprint of other users for consumers to compare.

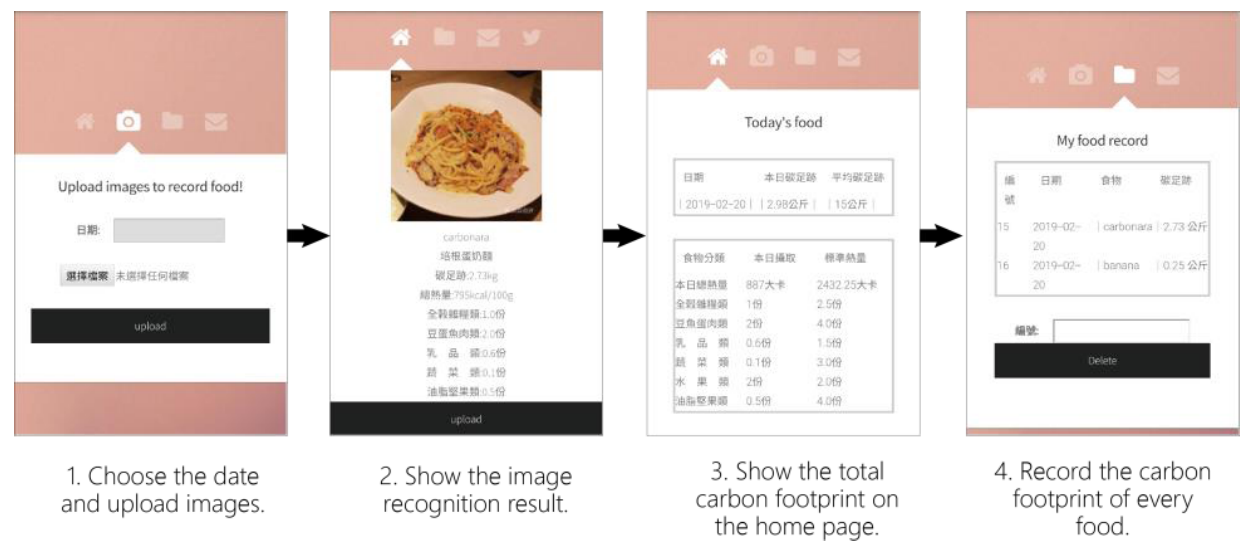

Figure 3. The user flow of website.

\subsection{The results of SUS}

Nielsen[17] pointed out that most of the usability problems can be found in the first 5 subjects. Therefore, this study recruited 5 subjects to participate the experiment. All of the subjects are college students and the results are showed in Table 2. As can be seen, the average SUS score is 88 and the standard deviation of SUS score is 3.71, which means that the website is useful and usable according to Sauro[14]. Moreover, Bangor [18] indicated that the SUS score in the range of 85-100 is considered to be excellent and the system is acceptable, as Figure 4 shows. Figure 5 is a test photo. 
Table 2. The results of SUS.

\begin{tabular}{|l|c|c|c|c|c|}
\hline & Subject 1 & Subject 2 & Subject 3 & Subject 4 & Subject 5 \\
\hline Sex & Male & Female & Male & Female & Female \\
\hline Age & 26 & 25 & 24 & 23 & 25 \\
\hline Score & 87.5 & 82.5 & 87.5 & 90 & 92.5 \\
\hline Average & \multicolumn{5}{|l}{} \\
\hline S.D & \multicolumn{7}{|l}{3.71} \\
\hline
\end{tabular}

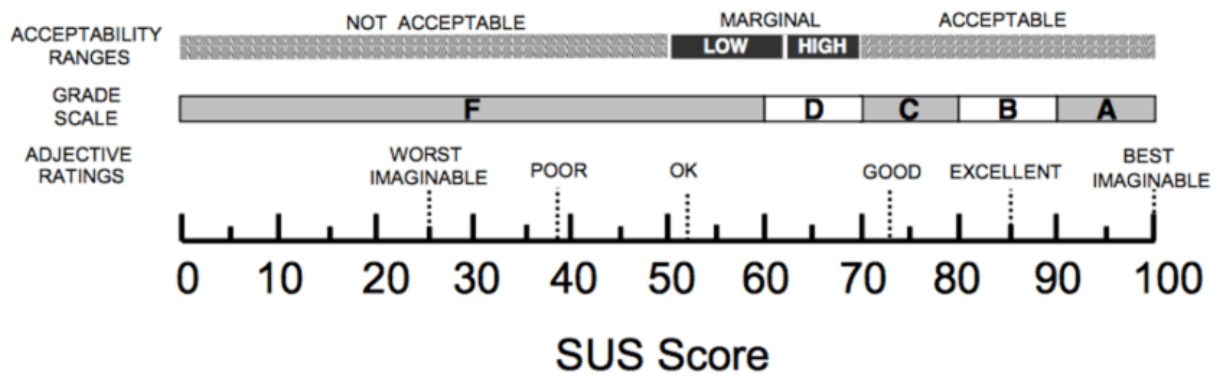

Figure 4. The adjective ratings of SUS scores [18].

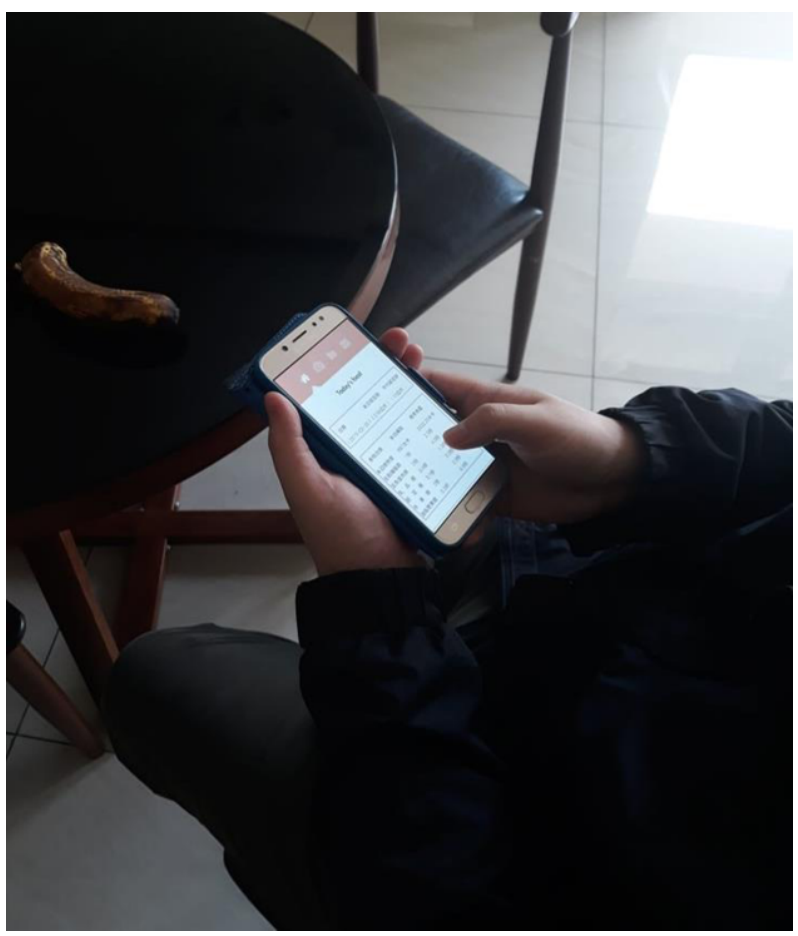

Figure 5. Test photo. 


\subsection{Discussion}

The contribution of this research is to apply new artificial intelligence technology to increase consumers' motivation to purchase green food. The green consumption related surveys in the previous literature like Chen[3] mostly refer to products with green label or carbon emission label, but the number of qualified foods are still a minority at present. Moreover, consumers may not be familiar with some green labels, as Judge[8] said, most consumers have positive attitudes towards the notion of sustainable housing, although they were relatively unfamiliar with specific sustainability certifications. Besides, consumers lack benchmarks between normal product and green product while obtaining information provided on the carbon labels. With the new system developed in this research, consumers can get the environment related information from both normal food and green food, and choose a lower carbon footprint one to eat.

$\mathrm{Zhu}[5]$ suggested governmental green food evaluation and education is needed; however, with the new system, carbon footprint information can be provided by nongovernmental company, which would be faster and more flexible. Also, this research uses a novelty method to show food carbon footprint and attract consumers to use, which is consistent with Maniatis[9]. The results of SUS score prove that the system is usable and acceptable for consumers.

However, there are some limitations in this research. Since the image recognition model used in this study is not mature enough for the identification of all types of food, it may lead to some error results, which may affect the user experience. In addition, according to the current technology, it is difficult to accurately measure the portions and origin of the food through the image. Therefore, the technical bottleneck may need to be improved by other means. For example, if the result is wrong, the record can be modified again. The carbon footprint displayed is assuming that the food are from the domestic, and the difference in mileage is not considered in this study.

\section{Conclusions}

\subsection{Research conclusions}

Applying deep learning image recognition technology to display greenhouse gas emission information can help consumers to go green when selecting food, and the website developed by this research can also display the six major types of food and show the daily basic calories to consumers. The daily calories can not only to record their own food carbon footprint, but also as a health management tool. The website will also display the daily average carbon footprint of all users using this platform, so that consumers can take it as a comparative standard, and then encouraged to lower the daily carbon footprint. Furthermore, unlike the traditional ways which manufacturers need to print the information or QR code on the product packages, the new method used in this study can reduce the cost of changing the packages, and it is easier to update the contents of the database rather than re-packaging.

\subsection{Future direction}

This study believes that with the help of new technologies and methods, it is possible to develop a recommendation system, calculate the similarity of food types, and 
recommend foods with low carbon footprint and similar nutrients to make the system more complete and greatly increase the convenience of usability in the future. At last, reducing the barrier between green consumption motivation and actual action so that consumers do not need to spend too much time thinking about and comparing the carbon footprint of each food when shopping. Another future research direction can focus on how to integrate behavior change models and theories such as gamification or the transtheoretical model to help consumers cultivate new sustainable consumption habits.

\section{References}

[1] Environmental Protection Administration, Executive Yuan, 2019, What is carbon footprint?, Accessed: 11.03.2019. [Online]. Available:

https://cfp.epa.gov.tw/carbon/ezCFM/Function/PlatformInfo/FLConcept/FLFootIntroduction.aspx

[2] Tutton, M. Cable News Network, 2018, Carbon emission to hit all-time high, says report, Accessed: 11.03.2019. [online]. Available:https://edition.cnn.com/2018/12/05/world/emissions-global-carbonbudget/index.html.

[3] P.-W. Chen, The Impact of Carbon Labeling on Consumer's Purchasing Decision, Master thesis, Institute of Environmental Engineering and Management of National Taipei University of Technology, 2010 .

[4] Lin, P-C and Huang, Y-H, The influence factors on choice behavior regarding green products based on the theory of consumption values, Journal of Cleaner Production, 2012, 22.1: 11-18.

[5] Q. Zhu, Y. Li, Y. Geng and Y. Qi, Green food consumption intention, behaviors and influencing factors among Chinese consumers, Food Quality and Preference, 2013, 28.1: 279-286.

[6] Y. Joshi and Z. Rahman, Factors affecting green purchase behaviour and future research directions, International Strategic management review, 2015, 3.1-2: 128-143.

[7] M. Motoshita, M. Sakagami, Y. Kudoh, K. Tahara and A. Inaba, Potential impacts of information disclosure designed to motivate Japanese consumers to reduce carbon dioxide emissions on choice of shopping method for daily foods and drinks, Journal of Cleaner Production, 2015, 101: 205-214.

[8] M. Judge, G. Warren-Myers and A. Paladino, Using the theory of planned behaviour to predict intentions to purchase sustainable housing, Journal of Cleaner Production, 2019, 215: 259-267.

[9] S. Lockie, K. Lyons, G. Lawrence and K. Mummery, Eating 'green': motivations behind organic food consumption in Australia, Sociologia ruralis, 2002, 42.1: 23-40.

[10] P. Maniatis, Investigating factors influencing consumer decision-making while choosing green products, Journal of Cleaner Production, 2016, 132: 215-228.

[11] S.N. Khan and M. Mohsin, The power of emotional value: Exploring the effects of values on green product consumer choice behavior, Journal of cleaner production, 2017, 150: 65-74.

[12] Google, 2019, Advanced Guide to Inception v3 on Cloud TPU, Accessed: 15.05.2019,[Online]. Available: https://cloud.google.com/tpu/docs/inception-v3-advanced

[13] CleanMetrics $^{\mathrm{TM}}, 2011$, FOOD CARBON EMISSIONS CALCULATOR, Accessed: 11.03.2019, [Online]. Available: http://www.foodemissions.com/foodemissions/Calculator.aspx.

[14] J. Sauro and J.R. Lewis, Quantifying the user experience: Practical statistics for user research. Morgan Kaufmann, Waltham MA, USA, 2012.

[15] Calculator.net, 2005, BMR Calculator, Accessed: 11.03.2019. [Online]. Available: https://www.calculator.net/bmr-calculator.html

[16] Health Promotion Administration, MOHW, Daily Diet Guide, Health Promotion Administration, Taipei, 2018.

[17] J. Nielsen and T.K. Landauer, A mathematical model of the finding of usability problems. Proceedings of the INTERACT'93 and CHI'93 conference on Human factors in computing systems. ACM, 1993: 206213

[18] A. Bangor, P. Kortum and J. Miller, Determining what individual SUS scores mean: Adding an adjective rating scale. Journal of Usability Studies, 2009, 114-123. 